\title{
Case descriptions of fibropapillomatosis in rehabilitating loggerhead sea turtles Caretta caretta in the southeastern USA
}

\author{
Annie Page-Karjian ${ }^{1, *}$, Terry M. Norton ${ }^{2}$, Craig Harms ${ }^{3}$, Doug Mader ${ }^{4}$, \\ Larry H. Herbst ${ }^{5}$, Nancy Stedman ${ }^{6}$, Nicole L. Gottdenker ${ }^{1}$
}

\author{
${ }^{1}$ University of Georgia, College of Veterinary Medicine, Department of Pathology, 501 D.W. Brooks Drive, Athens, GA 30602, USA \\ ${ }^{2}$ Georgia Sea Turtle Center, Jekyll Island Authority, 214 Stable Road, Jekyll Island, GA 31527, USA \\ ${ }^{3}$ North Carolina State University, Center for Marine Sciences and Technology and College of Veterinary Medicine, \\ Department of Clinical Sciences, 303 College Circle, Morehead City, NC 28557, USA \\ ${ }^{4}$ The Turtle Hospital, 2396 Overseas Highway, Marathon, FL 33050, USA \\ ${ }^{5}$ Albert Einstein College of Medicine, Department of Pathology and Department of Microbiology and Immunology \\ 1300 Morris Park Avenue, Bronx, NY 10461, USA \\ ${ }^{6}$ Busch Gardens Zoo Hospital, 3605 East Bougainvillea Avenue, Tampa, FL 33612, USA
}

\begin{abstract}
Fibropapillomatosis (FP) is a debilitating neoplastic disease that affects all species of hard-shelled sea turtles, including loggerhead turtles Caretta caretta. FP can represent an important clinical concern in rehabilitating turtles, since managing these infectious lesions often requires special husbandry provisions including quarantine, and FP may affect clinical progression, extend rehabilitation duration, and complicate prognoses. Here we describe cases of rehabilitating loggerhead turtles with FP (designated FP+). Medical records of FP+ loggerhead cases from 3 sea turtle rehabilitation facilities in the southeastern USA were reviewed. Between 2001 and 2014, FP was observed in 8 of 818 rehabilitating loggerhead turtles $(0.98 \%$ overall prevalence in admitted patients). FP+ loggerhead size classes represented were large juvenile (straight carapace length, SCL: $58.1-80 \mathrm{~cm}_{i} \mathrm{n}=7$ ) and adult (SCL $>87 \mathrm{~cm}_{i} \mathrm{n}=1$ ). Three turtles presented with $\mathrm{FP}$, and 5 developed tumors during rehabilitation within a range of 45 to $319 \mathrm{~d}$. Sites of new tumor growth included the eyes, sites of trauma, neck, and glottis. FP+ turtles were scored as mildly $(3 / 8)$, moderately $(4 / 8)$, or heavily $(1 / 8)$ afflicted. The mean total time in rehabilitation was $476 \pm$ 355 d (SD) (range: 52-1159 d). Six turtles were released without visible evidence of FP, 1 turtle was released with mild FP, and 1 turtle with internal FP was euthanized. Clinical decision-making for FP+ loggerhead patients can be aided by such information as time to tumor development, anatomic locations to monitor for new tumor growth, husbandry considerations, diagnostic and treatment options, and comparisons to FP in rehabilitating green turtles Chelonia mydas.
\end{abstract}

KEY WORDS: FP · CFPHV · ChHV5 - Rehabilitation · Epidemiology $\cdot$ Captive care $\cdot$ Survival outcomes Resale or republication not permitted without written consent of the publisher

\section{INTRODUCTION}

Fibropapillomatosis (FP) is a debilitating neoplastic disease of hard-shelled marine turtles, including loggerheads Caretta caretta (Herbst 1994), that causes cutaneous (Herbst 1994), ocular (Brooks et al. 1994, Flint et al. 2010), and internal (Jacobson et al. 1989, Norton et al. 1990, Herbst 1994) tumors. As in green turtles Chelonia mydas, FP tumors in loggerhead turtles usually develop on the soft skin, although FP may 
be observed on any part of a turtle's body, including all internal organs (Herbst 1994). Rapid tumor growth and subsequent disruption of afflicted turtles' biological functions may eventually lead to death in some individuals (George 1997). Hematological and biochemical abnormalities such as anemia, lymphocytopenia, neutrophilia, monocytosis, hypoproteinemia, and hyperglobulinemia have been observed in turtles with FP, indicating immunosuppression, chronic stress, and inflammation (Aguirre et al. 1995, Work et al. 2001, Page-Karjian et al. 2014). Transmission (Herbst et al. 1995) and molecular (Quackenbush et al. 1998, Lackovich et al. 1999) studies suggest that a herpesvirus (chelonid fibropapilloma-associated herpesvirus, CFPHV) is the etiologic agent of FP. The CFPHV genome was recently sequenced in its entirety (Ackermann et al. 2012). Viral sequence divergence suggests distinct viral lineages (Herbst et al. 2004, Patrício et al. 2012), and localized sequence homogeneity suggests cross-species transmission (Lackovich et al. 1999, Herbst et al. 2004) with loggerhead variants being most divergent (Herbst et al. 2004). Two other non-tumorigenic herpesviruses, viz. loggerhead genital-respiratory herpesvirus and loggerhead orocutaneous herpesvirus, exist in Florida, USA (Stacy et al. 2008).

FP is only sporadically reported in wild-caught loggerheads in the Western Atlantic (Herbst 1994, Quackenbush et al. 1998, Lackovich et al. 1999, Ene et al. 2005), For example, in South Carolina and Georgia during the time frame of this study, 2 of 946 $(0.2 \%)$ loggerheads caught by in-water trawl sampling had FP (diagnosis confirmed via histopathology; Maier et al. 2004). In Core and Pamlico Sounds, North Carolina, during the time frame of this study, FP was not observed in any of the 205 loggerhead turtles caught by in-water pound net sampling ( $\mathrm{J}$. Braun-McNeill pers. comm.). Although FP in loggerheads is not very common, it is of concern in a rehabilitation or captive setting because turtles with FP require extensive quarantine measures and tend to have more complicated prognoses due to poor nutritional condition, poor general health upon admission, and other opportunistic infections (bacterial, viral, fungal, or parasitic; Work et al. 2004, Stacy et al. 2008). FP tumors can develop after turtles are admitted for other reasons, and prolonged captivity of turtles with FP can exacerbate cycles of tumor removal and regrowth. These factors place a considerable burden on facilities and limit the number of turtles that can be treated (Page-Karjian et al. 2014). A recent survey of a rehabilitation facility in the southeastern USA reported that FP was present in 27 of
$362(7.5 \%)$ of all sea turtles admitted for rehabilitation during 2009 to 2013, either upon admittance or during their rehabilitation. Of those 27, 25 were green turtles and 2 were Kemp's ridleys Lepidochelys kempii (Page-Karjian et al. 2014). Loggerhead sea turtles, which are also susceptible to FP, are classified as threatened in the Northwest Atlantic region (NMFS \& USFWS 2011). To assess the effects of FP in rehabilitating loggerheads, we examined cases from 3 sea turtle rehabilitation facilities in the southeastern USA. These turtles belong to the Northwest Atlantic Endangered Species Act distinct population segment (DPS) and presumably to the northern regional management/recovery unit corresponding to beaches from Virginia through the Georgia/Florida border (Pearce 2001, NMFS \& USFWS 2008).

\section{MATERIALS AND METHODS}

\section{Rehabilitating loggerhead case data}

Medical records of all wild-caught loggerhead sea turtles undergoing rehabilitation at the Georgia Sea Turtle Center (Jekyll Island, Georgia), The Turtle Hospital (Marathon, Florida), and the Karen Beasley Sea Turtle Rescue and Rehabilitation Center (KBSTRR; Topsail Beach, North Carolina) between 2001 and $2014(\mathrm{n}=818)$ were reviewed to identify fibropapilloma-afflicted (FP+) cases. Case data for any FP+ loggerhead turtles were retrospectively evaluated and are reported here. The inclusion criteria for FP+ turtles in this study were admission as a loggerhead sea turtle patient to rehabilitation, presentation with or development of external FP tumors, and complete medical records including all observations and treatments, until time of release or necropsy. FP was diagnosed by the attending veterinarian based mainly on clinical signs; diagnoses were supported by histopathology and confirmation of presence of CFPHV polymerase (UL30) gene by PCR.

The following data were collected from medical records: sex, date of entry into rehabilitation facility, weight (in $\mathrm{kg}$ ), straight carapace length ( $\mathrm{SCL}$, in $\mathrm{cm}$ ) and width $(\mathrm{SCW}$, in $\mathrm{cm})$, body condition index $(\mathrm{BCI}=$ [weight/SCL ${ }^{3}$ ] $\times 10000$; Bjorndal et al. 2000), presenting complaint and co-morbid condition(s), days to onset of tumors, tumor location(s), highest tumor score, patient care, ancillary diagnostics, case outcome (euthanasia or release), and total duration of rehabilitation. Turtle size classes were categorized as follows: large juvenile (SCL 58.1-80 cm), sub-adult (80.1-87 cm), and adult (>87 cm; Crouse et al. 1987). 
BCI values were categorized as follows: very good $(>1.2)$, good (1.11-1.2), average (1.0-1.1), and poor $(<1.0$; Bjorndal et al. 2000). Tumor scores (1-3) were assigned as described in Table 1 (Balazs 1991, Work \& Balazs 1999, Page-Karjian et al. 2014).

\section{Data analysis}

Means and standard deviations were calculated for the following continuous data: weight, SCL, SCW, and BCI measurements at admission, time to tumor onset, and total time in rehabilitation. Percentages were calculated for categorical variables (i.e. presenting complaints, co-morbid conditions, case outcomes). Tumor locations on the turtles' bodies (i.e. dorsoanterior vs. posterior, head/neck, eyes, front flippers, inguinal skin, shell, tail/tail base, shell-skin interface, internal, wound site) were categorized and enumerated.

\section{RESULTS}

\section{Demographics and morphometrics}

Eight turtles ( 7 juveniles and 1 adult) had FP or developed FP during rehabilitation between 2001 and 2014. Mean \pm SD (range in parentheses) for SCL was $72.9 \pm 9.5 \mathrm{~cm}(65.9-92.6 \mathrm{~cm}), \mathrm{SCW}$ was $59.7 \pm$ $6.5 \mathrm{~cm}(51.4-69.3 \mathrm{~cm})$, weight was $47.8 \pm 11.8 \mathrm{~kg}$ $(37.3-72.6 \mathrm{~kg})$, and BCI was $1.4 \pm 0.17(1.18-1.62)$.

\section{Presenting complaints and co-morbid conditions}

Presenting complaints of the FP+ loggerheads included stranded (3/8), floating $(2 / 8)$, boat strike $(2 / 8)$, and hook ingestion (1/8). Co-morbid conditions included head trauma (2/8), edema (1/8), dyspnea $(1 / 8)$, debilitation (1/8), front flipper fracture (1/8), leech infestation (1/8), and puncture wound (1/8).

\section{Tumor onset, scores, location, and morphology}

Three turtles presented with lesions consistent with FP; 2 and 1 of these turtles had tumor scores 2 and 3 , respectively. Five turtles developed tumors within $7,23,38,43$, and $46 \mathrm{wk}$ of admission (mean \pm SD: $217 \pm 115 \mathrm{~d}$; range: $45-319 \mathrm{~d}$ ), usually during the warmer months ( $4 / 5$ turtles between April and September). In these 5 turtles, tumors were first observed on the eyes/eyelids, glottis, site of trauma, or neck, and highest tumor scores were $1(n=3)$ and $2(n=2)$.

Fifty percent of the turtles had ocular tumors followed by front flipper/shoulder, neck, and tail base ( 2 each), and glottis, head fracture lesion, plastron, and inguinal region (1 each). Six turtles had tumors only on the dorsoanterior body, and 2 had tumors on both the dorsoanterior and posterior body.

\section{Patient care}

The loggerhead patients described herein received the high standard of care afforded all sea turtle patients that are admitted to the 3 rehabilitation facilities included in the study. Once a diagnosis of FP was made, stringent quarantine measures were enforced to prevent potential disease transmission. The turtles were housed individually in $3 \mathrm{~m}$ diameter $\times$ $1.1 \mathrm{~m}$ depth tanks with independent water supplies $\left(25^{\circ} \mathrm{C}_{i} 30\right.$ ppt salinity), fitted with bead filtration and ozone disinfection. Ambient light periodicity ranged from 8 to $14 \mathrm{~h}$ in winter and summer, respectively, and tank water temperatures fluctuated mildly $\left(\sim 1-2^{\circ} \mathrm{C}\right)$ with season.

Table 1. Morphologic criteria used to assign tumor scores (0-3) to loggerhead turtles Caretta caretta in this study. Adapted from Table 1 in Page-Kajian et al. (2014); used by permission

\begin{tabular}{|c|c|c|c|c|c|c|}
\hline \multirow{2}{*}{$\begin{array}{l}\text { Tumor } \\
\text { score }\end{array}$} & \multirow{2}{*}{$\begin{array}{l}\text { General } \\
\text { description }\end{array}$} & \multirow[b]{2}{*}{ No. } & \multirow{2}{*}{\multicolumn{2}{|c|}{$\begin{array}{l}\text { Tumor details } \\
\text { Location }\end{array}$}} & \multirow[b]{2}{*}{ Morphology } & \multirow[b]{2}{*}{ Internal? } \\
\hline & & & & & & \\
\hline 0 & Unafflicted & 0 & - & - & - & No \\
\hline 1 & Mildly afflicted & $1-10$ & $0-1 \mathrm{~cm}$ & Skin or conjunctivae & Flat to slightly raised & No \\
\hline 2 & Moderately afflicted & $2-10$ & $\begin{array}{c}2-5 \mathrm{~cm} \mathrm{OR}>5 \mathrm{~cm} \\
\text { base } \leq 1 \mathrm{~cm}\end{array}$ & $\begin{array}{l}\text { Skin, shell, conjunctivae, } \\
\text { unilateral cornea, previous } \\
\text { tumor removal site }\end{array}$ & $\begin{array}{l}\text { Raised, proliferative, } \\
\text { and/or pedunculated }\end{array}$ & No \\
\hline 3 & Heavily afflicted & $>10$ & $>5 \mathrm{~cm}$ & $\begin{array}{c}\text { Skin, shell, conjunctivae, } \\
\text { bilateral corneae, } \\
\text { intraocular }\end{array}$ & $\begin{array}{l}\text { Severe, aggressive, } \\
\text { raised, proliferative/ } \\
\text { verrucous }\end{array}$ & Yes \\
\hline
\end{tabular}




\section{Antemortem diagnostics and necropsy results}

Radiographs, performed in all 8 turtles in this study, did not detect the internal tumors that were found in the 1 turtle that was necropsied. Computed tomography ( $\mathrm{CT}_{\text {; }}$ non-transportable) was used to evaluate for internal tumors in 2 turtles; it was instructive in diagnosing a lack of internal tumors in 1 turtle, and the presence of internal tumors in the other turtle, which was later confirmed via necropsy. The FP diagnosis was confirmed histologically in $100 \%$ of the FP+ loggerheads (Herbst 1994). PCR (Lu et al. 2000, Ene et al. 2005) was used in 6 of 8 turtles to amplify a $\sim 364$ bp portion of the UL30 gene, and all 6 tested positive; PCR product sequences were $100 \%$ homologous to multiple UL30 sequences from green and loggerhead turtles from Florida (GenBank accession numbers AY644454.1, AY646888.1, AY646889.1, AY395516.1, AF299110.1, AF035004.1, AF35005.1, AF120208.1). Additional PCR and sequencing of 3 CFPHV-positive samples verified that 2 cases had CFPHV variants A and B (GenBank AY646888.1 and AY646892.1, respectively), which are commonly detected in green turtles from the east coast of Florida, while the third one matched CFPHV variant D (GenBank AY646890.1), which so far has only been detected in loggerheads (Herbst et al. 2004, Ene et al. 2005).

\section{Tumor removal}

Seven FP+ loggerheads underwent 1 or more tumor removal surgeries. Overall, of the 18 total FP lesions that were surgically removed from 7 turtles, only 1 site resulted in tumor regrowth within $106 \mathrm{~d}$ after the initial surgery. This regrowth was self-limiting, and follow-up biopsy and histopathology diagnosed the regrowth lesions as regressing FP and scar tissue. Another turtle grew a new tumor in an unrelated site after the initial tumor removal procedure. For 1 turtle with severe FP, euthanasia was elected instead of tumor removal.

\section{Case outcomes}

The mean $( \pm \mathrm{SD})$ total time in rehabilitation for the $8 \mathrm{FP}+$ loggerheads was $476 \pm 355 \mathrm{~d}$ (range: $52-$ $1159 \mathrm{~d}$ ). Six turtles were released with no visible evidence of FP. One turtle, otherwise in robust health, was released with mild FP characterized by a single, $0.4 \mathrm{~cm}$, sessile, verrucous growth on the palmar surface of the right front flipper that remained unchanged in size and character for 2 mo prior to release. One turtle was euthanized following a diagnosis of internal tumors and a grave prognosis.

\section{Atypical, severe FP case}

In 1 case, the FP lesion severity, distribution, and morphology were markedly different from the other FP+ loggerhead cases. This adult female loggerhead had multifocal, moderate to severe FP lesions on the eyelids, neck, inguinal region, plastron, and tail base, covering approximately $50 \%$ of the skin. The turtle was anemic, intermittently anorectic, and dehydration, hepatic, and/or renal disease were suspected due to green plasma and persistently elevated plasma uric acid concentrations (i.e. $2.5 \mathrm{mg} \mathrm{dl}^{-1}$ ). There was minimal clinical response to treatment and supportive care, and humane euthanasia was elected when tumor biopsy, $\mathrm{PCR}$, and $\mathrm{CT}$ results indicated severe FP with internal tumors. Necropsy revealed subcutaneous and coelomic edema, small cysts and masses in the liver, gallstones, a flat and tortuous gallbladder, possible fibropapillomas in the stomach and colon, hyperemic small intestinal mucosa, a fibrous left kidney, and a cystic right kidney. Histologically, all 18 skin specimens suspected for FP were confirmed as such. The stomach and colon masses observed at necropsy were confirmed to be ulcerated fibropapillomas; and lesions in the lung, renal capsule, liver, skeletal muscle, adipose, trachea, and great vessels were diagnosed as atypical connective tissue proliferation consistent with the stromal component of typical FP. Fibropapilloma and blood samples collected antemortem, as well as the following tissues collected at necropsy (non-FP skin, oropharyngeal and cloacal epithelium, brain, spinal cord, nerve plexi, adipose, skeletal muscle, lung, kidney, heart, liver, spleen, pancreas, thymus, urinary and gall bladders, ovary and oviduct, stomach, small and large intestine) tested positive for UL30 via nested PCR. All PCRpositive samples had $100 \%$ sequence homology to Caretta caretta herpesvirus (Florida variant D, a putative loggerhead-specific variant; GenBank AF120208.1; Herbst et al. 2004, Ene et al. 2005).

\section{DISCUSSION AND CONCLUSIONS}

The FP prevalence data within the 3 sea turtle rehabilitation facilities show that only 8 of $818(0.98 \%)$ loggerheads treated at these facilities within the $13 \mathrm{yr}$ 
time frame of this study had or developed FP. Similarly to green turtle populations in the Northwest Atlantic DPS in which juveniles are the predominant FP-affected age class (Fick et al. 2000, Hirama \& Ehrhart 2007, Page-Karjian et al. 2014), the majority $(7 / 8)$ of the FP+ loggerheads discussed here were large juveniles. We can conclude based on these 8 cases that FP in rehabilitating loggerhead turtles tends to differ from FP in rehabilitating green turtles (e.g. Page-Karjian et al. 2014). In green turtles, FP tends to be severe and aggressive, associated with anemia and metabolic derangements, and can lead to death in certain individuals; in a study of 25 rehabilitating FP+ green turtles, $20 \%$ were tumor score 3 and $28 \%$ died or were euthanized (Page-Karjian et al. 2014). By comparison, FP in loggerheads is often considered more of an incidental finding: in the present study, only 1 of $8(12.5 \%)$ turtles was assigned tumor score 3 and was euthanized, while 7 of 8 (87.5\%) had mild or moderate tumors and were released. These data imply that rehabilitation efforts focused on FP+ loggerheads may have a more favorable outcome than those focused on FP+ green turtles; however, prognosis, treatment, and management decisions should be made on a case-by-case basis. The lower severity of FP in loggerheads relative to green turtles points to a possible host difference in disease susceptibility following CFPHV infection (Jacobson et al. 1991, Hirama \& Ehrhart 2007). While there is insufficient data to make a strong statistical association between the severity of disease and host specificity of CFPHV variant, it is worth noting that the putative loggerhead-specific variant D was found in the most severe FP case in our series, while the less severe cases were infected with more prevalent variants also found in green turtles. Despite the low prevalence, FP can still represent an important clinical concern in rehabilitating loggerheads, since managing these infectious lesions often requires special husbandry provisions including quarantine, and FP may affect clinical progression, extend rehabilitation duration, and complicate prognoses.

A subset (5/8) of turtles developed tumors after spending an average of $217 \mathrm{~d}$ (range $=45-319 \mathrm{~d}$ ) in rehabilitation; all of these turtles were patients at the KBSTRR facility. This time frame before tumor development is longer on average but similar in range to that of rehabilitating green turtles, for which an average time in rehabilitation before tumor development was $87 \mathrm{~d}$, with a range of 0-259 d (Page-Karjian et al. 2014). Such FP tumor development in captive turtles may be due to either viral recrudescence of latent herpesviral infections or recent viral infection (Young
\& Rickinson 2004, Work et al. 2009). Turtles at this facility were subjected to complete physical examinations upon entry, and thus it is unlikely that tumors were missed at admission. Due to limited space availability at KBSTRR prior to recent renovations, turtles were only quarantined after FP was diagnosed, and viral cross-contamination via splashing, aerosol, or fomites was an unavoidable possibility. There is no history of green turtles with FP at KBSTRR, so if infection did occur after the loggerheads entered rehabilitation, it was via subclinically infected turtles. More likely is the possibility that the turtles were already infected at the time of admission into rehabilitation, particularly given the fact that following experimental infection, Herbst et al. (1995) found that infected animals remained clinically normal for $7-43 \mathrm{wk}$. These findings highlight the importance of stringent quarantine measures in facilities housing captive sea turtles, including physical separation of green turtles from all other sea turtle species, and strict quarantine of all turtles with suspected or confirmed FP. In individual turtles, the most common sites of new tumor growth were the eyes, sites of trauma, neck, and glottis; these locations should be observed carefully in rehabilitating loggerheads for new tumor growth. Nearly all of those turtles that developed FP after entering rehabilitation did so during the warmer months; this agrees with another study in which most turtles inoculated with cell-free tumor extracts developed FP tumors between early February and May, when tank water temperatures became warmer, regardless of when they were inoculated (Herbst et al. 1995).

Most cases presented here had similar FP tumor scores and morphology: mild to moderate, single to multiple lesions consistent with the classical verrucous appearance of FP (Herbst 1994), addressed surgically and resolved thereafter. Similarly to studies of FP+ green turtles in which $36 \%$ (Page-Karjian et al. 2014) and $47.6 \%$ (Hirama \& Ehrhart 2007) had ocular tumors, $50 \%$ of FP+ loggerheads in our study had ocular tumors. The FP lesions reported here were predominantly located on the anterior portions of the turtles' bodies. Previous studies in FP+ green turtles reported greater total numbers of tumors present on either the anterior or posterior parts of FP+ turtles' bodies, or no difference (Adnyana et al. 1997, Work et al. 2004, Page-Karjian et al. 2014). Diagnostic CT provided high-quality cross-sectional images that were useful in this study for directing the course of therapy of FP+ patients, including diagnosis of internal tumors (Croft et al. 2004). Drawbacks of this diagnostic approach include cost, availability, and the 
fact that larger turtles may not fit into the CT machine. For the 7 turtles that underwent tumor removal surgery, a single procedure was adequate in 5 of 7 turtles for resolving the FP. In 1 case, the tumors appeared to be returning after surgery, but then stopped growing, regressed, and fell off before the animal was released. In another case, a new tumor growth was observed after the initial tumor removal surgery, but in a new location unrelated to the original FP site. Euthanasia candidacy and timing of release for $\mathrm{FP}+$ turtles are determined by the attending veterinarian according to clinical findings, medical opinion, and United States Fish and Wildlife Service permitting conditions. Release criteria should give utmost consideration to the animal's ability to survive in its current condition.

Acknowledgements. We thank the University of Georgia, College of Veterinary Medicine, for financial and interdisciplinary support. We thank the Georgia Sea Turtle Center staff, particularly Steven Nelson, Michelle Kaylor, Rachel Thomas, and Amy Hupp, for technical assistance; the Turtle Hospital, particularly Bette Zirkelbach, manager, and Richie Moretti, director; and volunteers at the Karen Beasley Sea Turtle Rescue and Rehabilitation Center, particularly Jean Beasley, director.

\section{LITERATURE CITED}

Ackermann M, Koriabine M, Hartmann-Fritsch F, de Jong PJ and others (2012) The genome of chelonid herpesvirus 5 harbors atypical genes. PLoS ONE 7:e46623

Adnyana W, Ladds PW, Blair D (1997) Observations of fibropapillomatosis in green turtles (Chelonia mydas) in Indonesia. Aust Vet J 75:736-742

Aguirre AA, Balazs GH, Spraker TR, Gross TS (1995) Adrenal and hematological responses to stress in juvenile green turtles (Chelonia mydas) with and without fibropapillomas. Physiol Zool 68:831-854

Balazs GH (1991) Current status of fibropapillomatosis in the Hawaiian green turtle, Chelonia mydas. In: Balazs GH, Pooley S (eds) Research plan for marine turtle fibropapilloma. Tech Memo NOAA-TM-NMFSSWFC156. US Dept Commerce, NOAA, NMFS, Honolulu, HI, p 47-57

Bjorndal KA, Bolten AB, Chaloupka MY (2000) Green turtle somatic growth model: evidence for density dependence. Ecol Appl 10:269-282

> Brooks DE, Ginn PE, Miller TR, Bramson L, Jacobson ER (1994) Ocular fibropapillomas of green turtles (Chelonia mydas). Vet Pathol 31:335-339

Croft LA, Graham JP, Schaf SA, Jacobson ER (2004) Evaluation of magnetic resonance imaging for detection of internal tumors in green turtles with cutaneous fibropapillomatosis. J Am Vet Med Assoc 225:1428-1435

Crouse DT, Crowder LB, Caswell H (1987) A stage-based population model for loggerhead sea turtles and implications for conservation. Ecology 68:1412-1423

- Ene A, Su M, Lemaire S, Rose C and others (2005) Distribu- tion of chelonid fibropapillomatosis-associated herpesvirus variants in Florida: molecular genetic evidence for infection of turtles following recruitment to developmental neritic habitats. J Wildl Dis 41:489-497

Fick K, Redlow T, Foley A, Singel K (2000) The distribution of stranded green turtles with fibropapillomas in the eastern United States, 1980-1998. In: Kalb H, Wibbels T (comps) Proc 19th Annu Symp Sea Turtle Biol Conserv. Tech Memo NMFS-SEFSC-443. US Dept Commerce, NOAA, South Padre Island, TX, p 236-237

Flint M, Limpus CJ, Patterson-Kane JC, Murray PJ, Mills PC (2010) Corneal fibropapillomatosis in green sea turtles (Chelonia mydas) in Australia. J Comp Pathol 142: 341-346

George RH (1997) Health problems and disease of sea turtles. In: Lutz PL, Musick JA (eds) The biology of sea turtles. CRC Press, Boca Raton, FL, FL p 363-385

> Herbst LH (1994) Fibropapillomatosis of marine turtles. Annu Rev Fish Dis 4:389-425

> Herbst LH, Jacobson ER, Moretti R, Brown T, Sundberg JP, Klein PA (1995) Experimental transmission of green turtle fibropapillomatosis using cell-free tumor extracts. Dis Aquat Org 22:1-12

Herbst LH, Ene A, Su M, Desalle R, Lenz J (2004) Tumor outbreaks in marine turtles are not due to recent herpesvirus mutations. Curr Biol 14:R697-R699

Hirama S, Ehrhart LM (2007) Description, prevalence and severity of green turtle fibropapillomatosis in three developmental habitats on the east coast of Florida. Fla Sci 70:435-448

Jacobson ER, Mansell JL, Sundberg JP, Hajjar L and others (1989) Cutaneous fibropapillomas of green turtles (Chelonia mydas). J Comp Pathol 101:39-52

Jacobson ER, Buergelt C, Williams B, Harris RK (1991) Herpesvirus in cutaneous fibropapillomas of the green turtle Chelonia mydas. Dis Aquat Org 12:1-6

Lackovich JK, Brown DR, Homer BL, Garber RL and others (1999) Association of herpesvirus with fibropapillomatosis in the green turtle Chelonia mydas and the loggerhead turtle Caretta caretta in Florida. Dis Aquat Org 37 : 89-97

> Lu Y, Wang Y, Yu Q, Aguirre AA, Balazs GH, Nerurkar VR, Yanagihara R (2000) Detection of herpesviral sequences in tissues of green turtles with fibropapilloma by polymerase chain reaction. Arch Virol 145:1885-1893

Maier P, Segar A, Arendt M, Whitaker J, Stender B, Parker L (2004) Development of an index of sea turtle abundance based upon in-water sampling with trawl gear. www. dnr.sc.gov/seaturtle/Literature/2004-inwater-final.pdf (accessed 15 March 2014)

NMFS (National Marine Fisheries Service), USFWS (US Fish and Wildlife Service) (2008) Recovery plan for the Northwest Atlantic population of the loggerhead sea turtle (Caretta caretta), 2nd rev. NMFS, Silver Spring, MD

NMFS, USFWS (2011) Endangered and threatened species: determination of nine distinct population segments of loggerhead sea turtles as endangered or threatened. Fed Regist 76:58868-58952

Norton TM, Jacobson ER, Sundberg JP (1990) Cutaneous fibropapillomas and renal myxofibroma in a green turtle, Chelonia mydas. J Wildl Dis 26:265-270

Page-Karjian A, Norton TM, Krimer P, Groner M, Nelson SE, Gottdenker NL (2014) Factors affecting survivorship in rehabilitating green sea turtles (Chelonia mydas) with fibropapillomatosis. J Zoo Wildl Med 45:507-519 
Patrício AR, Herbst LH, Duarte A, Vélez-Zuazo X and others (2012) Global phylogeography and evolution of chelonid fibropapilloma-associated herpesvirus. J Gen Virol 93: 1035-1045

Pearce AF (2001) Contrasting population structure of the loggerhead turtle (Caretta caretta) using mitochondrial and nuclear DNA markers. Masters thesis, University of Florida, Gainesville, FL

Quackenbush SL, Work TM, Balazs GH, Casey RN and others (1998) Three closely related herpesviruses are associated with fibropapillomatosis in marine turtles. Virology 246:392-399

Stacy BA, Wellehan JF, Foley AM, Coberly SS and others (2008) Two herpesviruses associated with disease in wild Atlantic loggerhead sea turtles (Caretta caretta). Vet Microbiol 126:63-73

Editorial responsibility: Alex Hyatt, Geelong, Victoria, Australia
Work TM, Balazs GH (1999) Relating tumor score to hematology in green turtles with fibropapillomatosis. J Wildl Dis 35:804-807

> Work TM, Rameyer RA, Balazs GH, Cray C, Chang SP (2001) Immune status of free-ranging green turtles with fibropapillomatosis from Hawaii. J Wildl Dis 37:574-581

- Work TM, Balazs GH, Rameyer RA, Morris RA (2004) Retrospective pathology survey of green turtles Chelonia mydas with fibropapillomatosis in the Hawaiian islands, 1993-2003. Dis Aquat Org 62:163-176

Work TM, Dagenais J, Balazs GH, Schumacher J and others (2009) In vitro biology of fibropapilloma-associated turtle herpesvirus host cells in Hawaiian turtles. J Gen Virol 90: 1943-1950

Young LS, Rickinson AB (2004) Epstein-Barr virus: 40 years on. Nat Rev Cancer 4:757-768

Submitted: August 25, 2014; Accepted: April 16, 2015

Proofs received from author(s): July 31, 2015 